\title{
The Online Moral Paradox: Understanding the Benefits of Downloadable Content on the Performance of Students in the Design Studio
}

\author{
MAGDY MOHAMED IBRAHIM \\ Abu Dhabi University
}

\author{
SADEKA SHAKOUR \\ Abu Dhabi University
}

This paper investigates the students' habits of using online resources in educational environments. The purpose of the study is to understand the extent that the new medium provides and the extent of benefits to students' learning.

Resources that are useful to professionals might not be as helpful to students who are supposed to draft and model the most mundane elements of their work themselves. However, students do have access to the same resources professional have with no difference nor guidance.

From an academic standpoint, student users might treat those content websites as normal go-to locations to obtain readymade solutions.

Does it make a difference to the quality of the students' work?

What is the moral reference for such behavior? How much of such behavior should be acceptable? How can we regulate the online interaction without scientific authority?

\section{INTRODUCTION}

The rise of the social networks and the recent development of digital technologies enhanced many aspects of the education of architecture. However, it created new complexities as well. The simple availability of such online resources has created an educational and moral paradox.

One question persists; is there anything like positive plagiarism? In other words, is using ready-made digital CAD components considered plagiarism? Can downloading and using ready-made components be beneficial? In fact, it might, at least for professionals who are not expected to waste time building models or drafting typical details that are so mundane (Fane 2015). It is not considered as applicable to students of architecture who are supposed to draft or model the most mundane elements of their work themselves. However, students do have access to the same resources professional have with no difference nor guidance which raises many concerns regarding integrity and educational benefits. Even though a professional would use ready-made components to complete a design assignment, students are always encouraged to produce their developed libraries.
The Internet and the World Wide Web have opened new avenues for research misconduct. They have also opened new avenues to discovery (Evans. 2016). Even the way course design is fashioned is changing daily to include innovative ways to promote learning and scholarly discussion using the Internet. Some argue that this will promote misconduct. Others believe that it will combat it (Evans 2000).

Students at the university level are expected to be able to learn on their own. They are supposed to be mature enough to filter useful content. Moreover, they are expected to adhere to academic integrity standards as well.

We can also observe that students are using the online resources in an unconventional way: They download and use ready-made blocks/components/objects. From door blocks to technical details, from furniture models to full floor plans, the user looking for such content can find it all free or almost free of charge.

Despite the apparent correlation, that using such resources would enhance the quality of the students' design product, the researchers wanted an evidence of the effect that such behavior grants them that advantage.

The argument for the moral of the act would come after determining if there is an actual benefit, and would also come after determining if this act is against academic integrity.

\section{THE HYPOTHESIS}

The hypothesis of the research is: Students benefits from using online downloadable resources. The quality of the design the student produce is relative to the freedom given to them to utilize online resources.

If a correlation is established, the question would be whether using such resources is in direct conflict with academic standards and integrity.

Then, if it is agreeable that students should benefit from the plethora of resources available today, a further discussion should start regarding how to monitor and regulate such usage to ensure fairness and integrity. 
In this paper, the researchers focused on investigating the correlation between the use of the content and the quality of the design output.

\section{ASSUMPTIONS}

To experiment, the researchers had assumed specific facts:

1. Students are excellent in finding online resources.

2. Students are good at utilizing CAD tools such as AutoCAD, SketchUp, 3DS MAX as well Photoshop

3. Students are experienced in design studios. By their third year, they would have completed four design studios where diverse issues are tackled, and a distinct set of skills have been acquired.

4. The amount of downloaded content might vastly vary between mundane objects that are used as entourage, objects of famous designers such as designer chairs, to complexly modeled curtains, sofas, classic or modern furniture which is difficult for mainstream users to model themselves, or at least requires considerable time to achieve.

5. Faculty members might not be able to easily differentiate between the product of the student him or herself and downloaded content. Despite the awareness of the faculty, it has always been astonishing the number of new sites emerging daily, and the savviness of the students finding them far beyond the capacity of experienced faculty members.

\section{THE EXPERIMENT}

A group of 32 students was assigned a design problem structured to test their ability to solve a distinct space planning problem.

The students were senior students selected as the third and fourth year of the Interior Design program. Their design ability varied as well as their overall cumulative GPA.

The students were randomly divided into three groups with specific instructions:

- Group A, was restricted to working entirely offline, utilizing any CAD design tool at their disposal, without resorting to any other resources.

- Group B was instructed to use any CAD design tool at their disposal and was allowed a total of $20 \%$ downloadable material from the web such as readymade components and such. The calculation of the $20 \%$ was an approximation measure. It was meant to restrict the feeling of being at ease to use what is liked. The researchers tried several measurement techniques that failed to be truly objective in evaluating the amount of the used

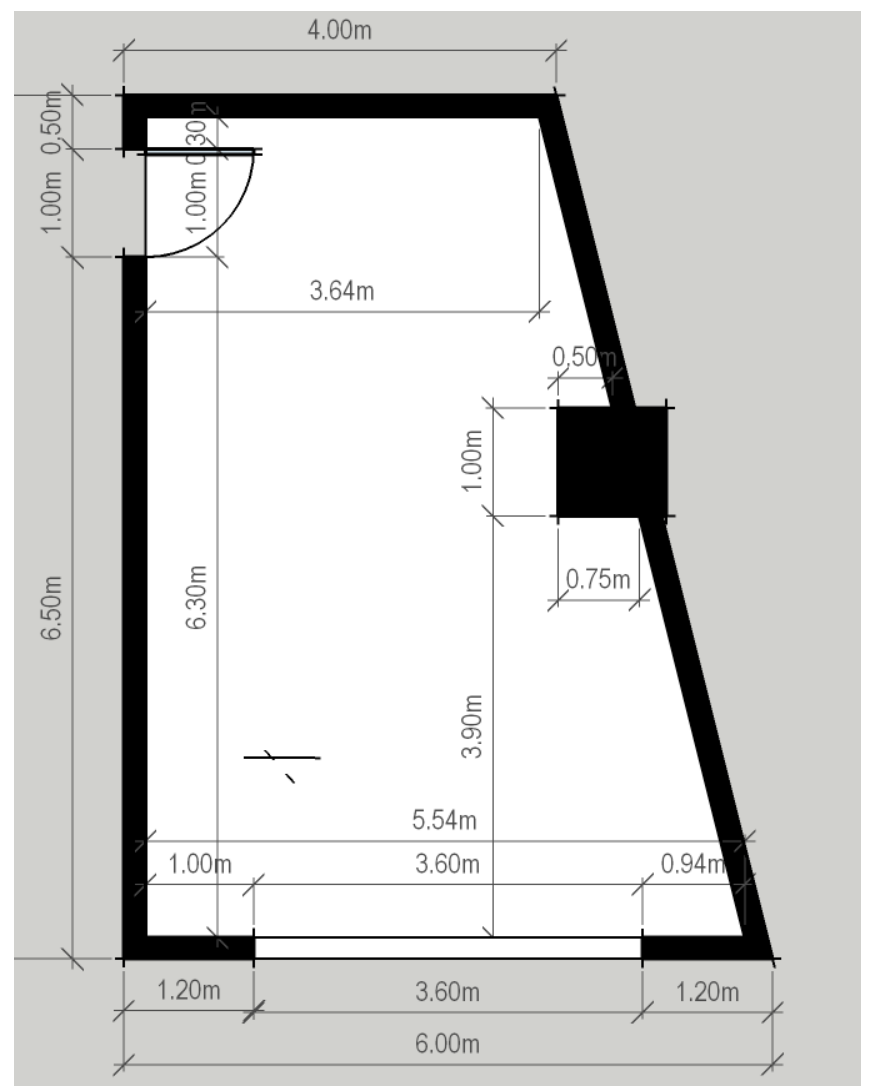

Figure 1: the assignment plan.

material. Hence the restriction was more of a mental restriction than an actual one.

- Group C was not confined to any restrictions. They were asked to solve the design problem without being directed regarding the use of tools nor resources.

The assigned design problem was to plan, design, and furnish a room to be used as a faculty lounge (Figure 1).

Despite the fictional nature of the problem, students were familiar with such a setting due to their previous training.

The plan at hand had an odd angled wall and an oversized column making it somewhat difficult to arrange simple furniture to achieve the solution. It was expected to call for specific solutions which had to be modeled and drafted specifically for this case.

The time allocated to the whole exercise was 24 hours, including 6 hours in the studio with teaching assistants. Students started the on one afternoon and digitally submitted their solution at the same time the next day.

After finishing the design, an exhibit of the project was set up for faculty members of the department to assess the design quality. 


\section{Group Assignment versus Grade}

Slope: 2.463 ; Intercept 74.065

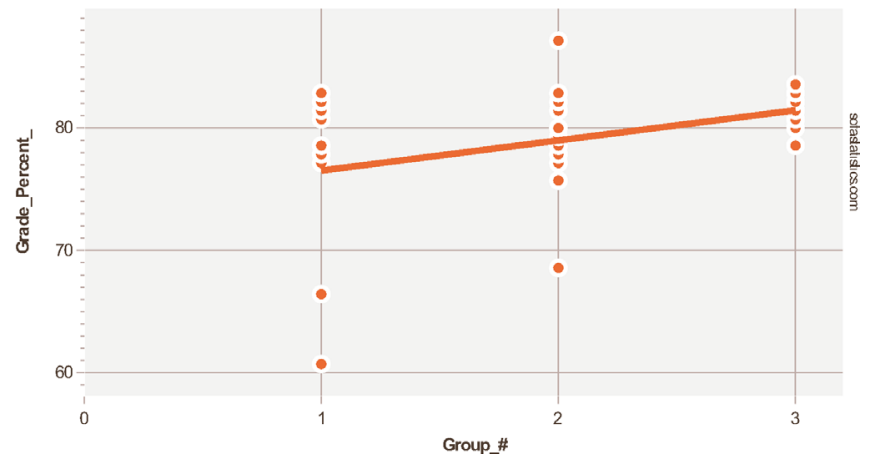

Figure 2: the grades correlated with the different groups where 1 represents group A, 2 represents group B, and 3 represents group C

Group Assignment versus Grade

Categorized by CGPA

2.0: Slope: 1.582 ; Intercopt 76.582

30: Slope: 1.239 ; interoept 78.469

3.5: Slope: 2.361 ; interoept 72.5

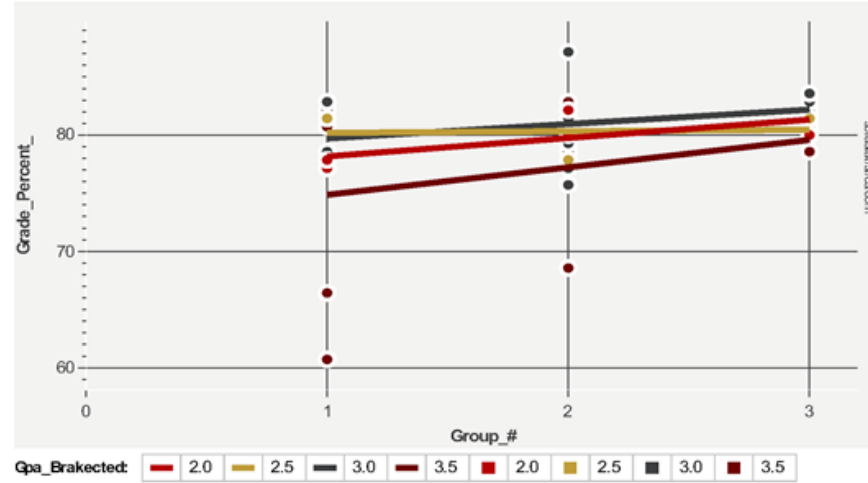

Group Assignment versus Grade

Categorized by seniority

1.0: Slope: 1.504 ; Intercept: 76.25

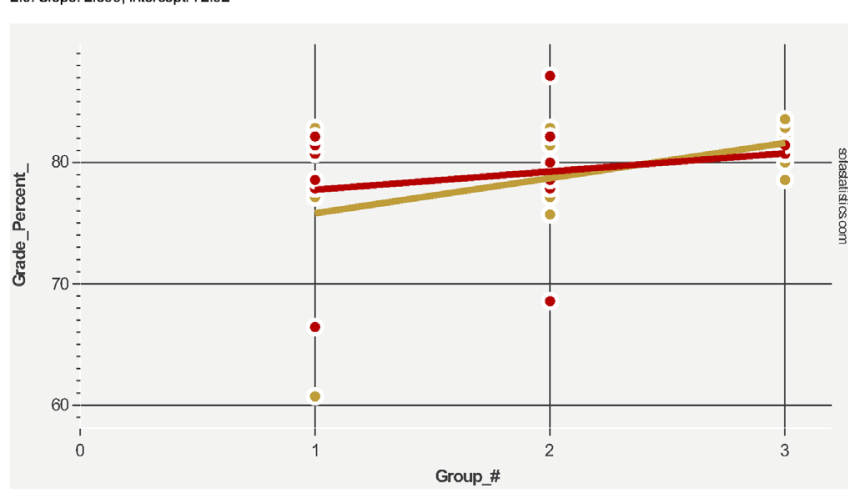

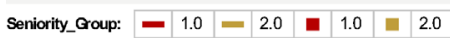

Figure 3: the chart categorized by the seniority group where group \# 1, in red, is the older cohort (4th year)

\section{Group Assignment versus Grade}

Categorized by Design ability measure from previouos studio progress

1.0: Slope: 2.269 ; Intercopt 74.202

3.0: Slope: 1.807: inturoept 75.943

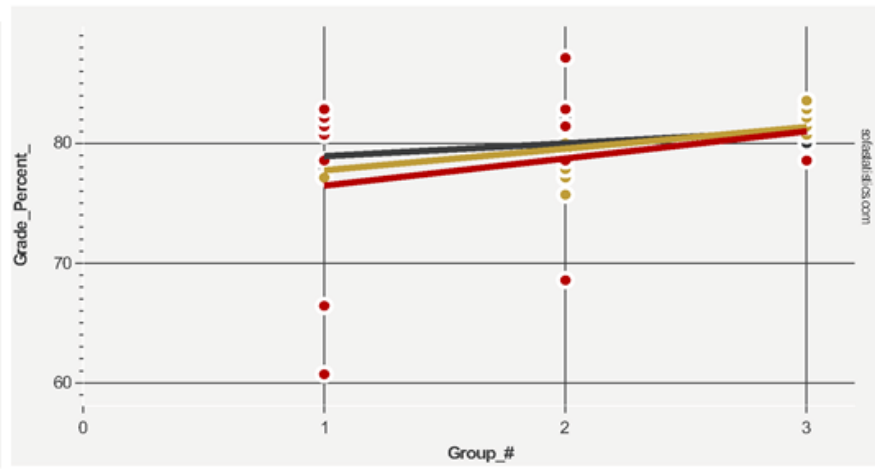

Design_Excellince: $-1.0=2.0-3.0=1.0$ |

Figure 4: to the left, The grades according to the CGPA of the students. To the right, Design skill determined from previous studios charted against the grades obtained where 1 is the best skill, 2 is the average and 3 represent the weak designers.

1.0: Slope: 1.58 ; Intercept: 74.78

3.0: Slope: 0.714 ; Intercept: 79.898

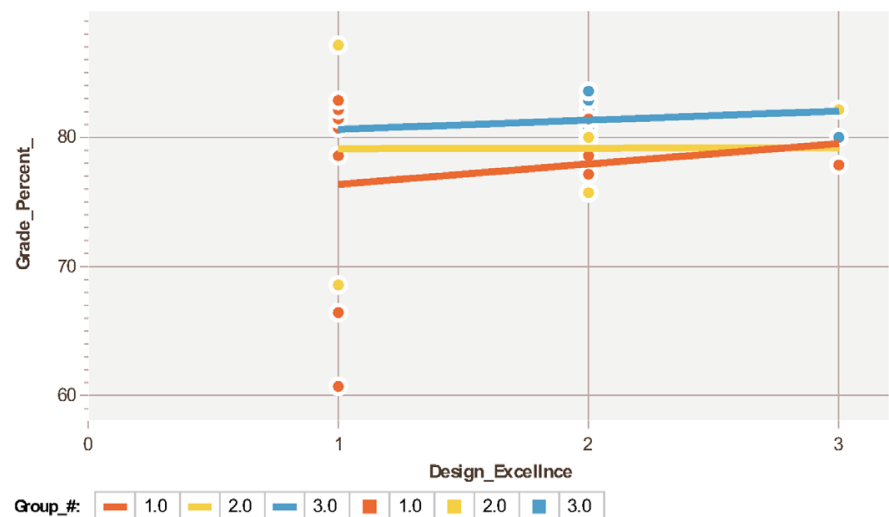

Figure 5: comparing the design skill against the grades, categorized by the three groups. Design excellence number 1 represents the best ability, 2 is the average, and 3 is weakest. 
The Department of Architecture and Design runs two programs; one of the Architecture and another of Interior Design. The faculty teaches in both programs with dedicated Interior Design faculty for particular subjects pertaining to Interior Design.

A simple grading scheme of $A, B+, B, C+, C$, and $D$ was used in the assessment. The assessment rubric included both the quality of design and the quality of communication.

Nine faculty members helped in the assessment process; their grades were compiled and compared to the various groups discussed earlier, the quality of the students' design skill measured from previous studios as well as their CGPA.

\section{THE RESULTS}

Using statistical tools, the researcher constructed a correlation between the score each student achieved and their assigned group.

The first result (Figure 2) showed a clear correlation between the performance of the student and the amount of freedom available to them to use online resources. The result was expected, but the breakdown of the groups and their design capacity established from previous studios revealed unexpected results.

When the seniority of the students was categorized (Figure 3), a clear difference got revealed; the younger cohort benefited more from the freedom available to them than the older cohort.

Another breakdown per cumulative GPA revealed another distinction (Figure 4).

The students with the highest CGPA were generally the least achievers in this assignment. Since CGPA is not a measure of the quality of design skill, the results were categorized a fourth time by the design ability of the students established from previous studio grades and broken down into three categories of excellence.

A comparison between the strength of the design skill of the student and the amount benefited is charted. The chart shows evidence that the best students achieved the most as expected, yet they were the least among who benefited from the freedom to use online resources.

In figure 5, a different story is observed, where the students with the best design skills performed the least across the three groups. The students in the restricted group A performed the worst among all the students, with some of them being the absolute worse. They were also the least beneficial among the free group $C$. The other group B was not affected.
Statistical significance:

Results of Spearman's Test of Linear Correlation

p-value: 0.06494

Spearman's $R$ statistic: 0.33

Degrees of Freedom (df): 30

Linear Regression Details:

- Slope: 1.942

- Intercept: 75.427

\section{DISCUSSIONS:}

The experiment results indicated a clear general tendency for the students to achieve better grades when they are allowed to use online resources beyond their capacity to model. There are several intricate differences between their performance depending on their seniority and their established design skill.

Students with high design skill when deprived the leverage of the online content could not perform as well as their peers who were allowed access to online content, which constitutes a solid indicator to the dependency on that content. It is confusing to interpret this result from a moral standpoint.

It is not believed that the students violated any rules of academic integrity, but the uncertainty regarding where the strength of their submissions is coming from triggers the moral paradox.

Combining the findings of figures 4 indicates an obvious conclusion where the strong students are more capable of using all the tools at hand to generate and communicate better designs despite their overall less achievement. Smarter students use tools in a smarter way.

Exceptional circumstances in performance cannot be ruled out in such a limited experiment, circumstances which might skew the results unexpectedly. Such unseen circumstances might explain the odd performance of the best students and might as well enforce the hypothesis of the research and more accentuate the moral paradox.

As previously discussed, professional do depend on readymade content, especially in Interior Design, to achieve the desired design outcome. It is almost unpractical to expect a professional to be savvy in $3 \mathrm{~d}$ modeling for instance enough to produce a complex classical piece of furniture.

As long as the design process is not compromised by any act of copying, it is always considered acceptable. But professional 
practice settings is different from academic settings. Since it is hard to determine the amount of external content used in an objective way, the judgment of the faculty on the quality of the students' production might not be as accurate as desired.

It is also clear that the exposure of the faculty professor to the market and their following of the latest in the field together with a very close monitoring of the students in the studio and a thorough follow up on every step would eliminate wrongdoings, but the case with evaluating written material highlights that difficulty and shows the need for some other tools beyond the mere experience of the professor.

The online paradigm shift has exponentially widened the scope of what can be obtained, and the speed of growth and development defies the efforts done to be up to date. Even the words "up to date" might have a different meaning now.

\section{CONCLUSION AND LESSONS LEARNED:}

Despite the amazing advancement of the communication technology, there are still some dark corners that might spoil the benefits. The online life of students is a fact that cannot be ignored. The students' ability to take advantage of online resources differs significantly, and surrendering the control to students is not advisable. There are ways to engage actively in the students' online life that can improve and regulate their experience. It is crucial to see the online resources from the same perspective as the students to be able to adjust what is necessary to their learning process.

Some other concerns would still linger such as; can there be a system to check the originality of a design against available content the way many online services check a written paper for authenticity?

How can studio professor ensure the authenticity of the students' output provided taking into consideration the original assumptions of this paper where it is believed that faculty members are well-experienced teachers.

\section{ENDNOTES}

1 Barkhuus, Louise, and Juliana Tashiro. "Student Socialization in the Age of Facebook." In Proceedings of the SIGCHI Conference on Human Factors in Computing Systems, 133-142. CHI '10. New York, NY, USA: ACM, 2010. doi:10.1145/1753326.1753347.

2 Boyd, Danah M., and Nicole B. Ellison. "Social Network Sites: Definition, History, and Scholarship." Journal of Computer-Mediated Communication 13, no. 1 (October 1, 2007): 210-30. doi:10.1111/j.1083-6101.2007.00393.x.

3 Espinoza, Verónica Paola Rossado. "Las Redes Sociales Como Apoyo a La Realización Del Proyecto Arquitectónico En El Ámbito Universitario [Social Network to Support the Development of the Architecture Project in the University]." SIGraDi 2012 Proceedings of the 16th Iberoamerican Congress of Digital Graphics Brasil - Fortaleza 13-16 November 2012, Pp. 104-108, 2012.

4 Evans, Jim. "The New Plagiarism in Higher Education: From Selection to Reflection," n.d.http://www2.warwick.ac.uk/services/ldc/resource/interactions/issues/issue11/evans. Issue 11, Volume 4, No. 2 - Summer Term 2000

5 Fane, Bill “The Power of Positive Plagiarism | Cadalyst." 2015. Accessed September 13. http://www.cadalyst.com/cad/autocad/ the-power-positive-plagiarism-4763.
6 "History of the Internet, Internet for Historians." Accessed June 22, 2016. http://www.let.leidenuniv.nl/history/ivh/frame_theorie.html.

7 Hoseini, Ali Ghaffarian; Rahinah Ibrahim. "Using Social Network Analysis for Visualising Spatial Planning During Conceptual Design Phase." CAADRIA 2007, Proceedings of the 12th International Conference on Computer Aided Architectural Design Research in Asia, Nanjing (China) 19-21 April 2007, 2007.

8 K, QaQish ; Ra'Ed. "15 Years of CAD Teaching in Jordan: How Much Has Been Accomplished? A Comparative Analysis of the Use of CAD in Architectural Schools Between 1997 and 2012." Achten, Henri; Pavlicek, Jiri; Hulin, Jaroslav; Matejovska, Dana (Eds.), Digital Physicality - Proceedings of the 30th eCAADe Conference - Volume 2 / ISBN 978-9-4912070-3-7, Czech Technical University in Prague, Faculty of Architecture (Czech Republic) 12-14 September 2012, Pp. 23-32, 2012.

9 Kirkpatrick, David. The Facebook Effect: The Inside Story of the Company That Is Connecting the World. Unknown edition. New York: Simon \& Schuster, 2011.

10 Marsh, Bill. Plagiarism: Alchemy and Remedy in Higher Education. Albany: State University of New York Press, 2007.

11 "Guidelines on Plagiarism - Department of Architecture." Page. Accessed October 3, 2015. http://www.arct.cam.ac.uk/plagiarism/.

12 Simon, Phil, and Mitch Joel. The Age of the Platform: How Amazon, Apple, Facebook, and Google Have Redefined Business. Revised edition. Las Vegas: Motion Publishing, 2011

13 "Plagiarism in Design - G132 History \& Analysis of Design." 2015. Accessed September 13. https://sites.google.com/site/g132historyanalysisofdesign/ Course-Resources/plagiarism-in-design-1.

14 Schnabel, Marc Aurel; Jeremy J. Ham. 2014. "The Social Network Learning Cloud: Architectural Education for the 21st Century." International Journal of Architectural Computing Vol. 12 - No. 3, 225-242.

15 University of Cambridge, Department of Architecture. 2015. "Guidelines on Plagiarism - Department of Architecture." Page. Accessed October 3. http:// www.arct.cam.ac.uk/plagiarism/.

16 "Usenet." Wikipedia, the Free Encyclopedia, June 9, 2016. https://en.wikipedia. org/w/index.php?title=Usenet\&oldid=724452836. 